\title{
Tobacco retail outlet restrictions: health and cost impacts from multistate life-table modelling in a national population
}

\author{
Amber L Pearson, ${ }^{1,2}$ Christine L Cleghorn, ${ }^{1}$ Frederieke $S$ van der Deen, ${ }^{1}$ \\ Linda J Cobiac, ${ }^{1,3}$ Giorgi Kvizhinadze, ${ }^{1}$ Nhung Nghiem, ${ }^{1}$ Tony Blakely, ${ }^{1}$ Nick Wilson ${ }^{1}$
}

\begin{abstract}
- Additional material is published online only. To view please visit the journal online (http://dx.doi.org/10.1136/ tobaccocontrol-2015-052846).

\section{${ }^{1}$ Burden of Disease}

Epidemiology, Equity and Cost Effectiveness (BODE ${ }^{3}$ ) Programme, University of Otago, Wellington, New Zealand ${ }^{2}$ Department of Geography, Michigan State University, East Lansing, Michigan, USA ${ }^{3}$ Nuffield Department of Population Health, British Heart Foundation Centre on Population Approaches to NCD Prevention, University of Oxford, Oxford, UK
\end{abstract}

\section{Correspondence to} Dr Amber L Pearson, Burden of Disease Epidemiology, Equity and Cost Effectiveness $\left(\mathrm{BODE}^{3}\right)$ Programme, University of Otago 23A Mein Street, Wellington 6242, New Zealand: apearson@msu.edu

Received 23 November 2015 Revised 25 August 2016 Accepted 31 August 2016 Published Online First 22 September 2016

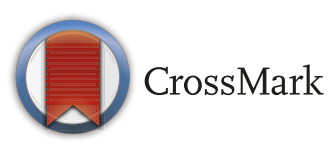

To cite: Pearson $A L$, Cleghorn $C L$, van der Deen FS, et al. Tob Control 2017;26:579-585.

\section{ABSTRACT}

Background Since there is some evidence that the density and distribution of tobacco retail outlets may influence smoking behaviours, we aimed to estimate the impacts of 4 tobacco outlet reduction interventions in a country with a smoke-free goal: New Zealand (NZ).

Methods A multistate life-table model of 16 tobaccorelated diseases, using national data by sex, age and ethnicity, was used to estimate quality-adjusted life years (QALYs) gained and net costs over the remainder of the 2011 NZ population's lifetime. The outlet reduction interventions assumed that increased travel costs can be operationalised as equivalent to price increases in tobacco.

Results All 4 modelled interventions led to reductions of $>89 \%$ of current tobacco outlets after the 10 -year phase-in process. The most effective intervention limited sales to half of liquor stores (and nowhere else) at 129000 QALYs gained over the lifetime of the population (95\% UI: 74100 to 212000 , undiscounted). The per capita QALY gains were up to 5 times greater for Māori (indigenous population) compared to non-Māori. All interventions were cost-saving to the health system, with the largest saving for the liquor store only intervention: US $\$ 1.23$ billion (95\% UI: $\$ 0.70$ to $\$ 2.00$ billion, undiscounted).

Conclusions These tobacco outlet reductions reduced smoking prevalence, achieved health gains and saved health system costs. Effects would be larger if outlet reductions have additional spill-over effects (eg, smoking denormalisation). While these interventions were not as effective as tobacco tax increases (using the same model), these and other strategies could be combined to maximise health gain and to maximise cost-savings to the health system.

\section{INTRODUCTION}

Many countries have aspirations of reducing or ending the burden of tobacco-related harm to their populations. National policies have been implemented to support these aspirations, including tobacco taxation, mass media campaigns and advertising restrictions. New Zealand (NZ) is one such country, with an established national smoke-free goal for the year $2025^{1}$ and recent progress in reducing adult daily smoking rates (falling from $21 \%$ to $15 \%$ from 2006 to 2013$).^{2}$ Owing to the availability of rich epidemiological and health system cost data, the limited problems with illicit tobacco $^{3}$ and the national interest in 'endgame' strategies, NZ is a plausible setting to explore interventions that might make contributions towards achieving very low smoking prevalence or even a smoke-free society.

There is some evidence that ready access to tobacco retailers influences smoking initiation and cessation. ${ }^{4-10}$ As such, there is growing interest in reducing the quantity and/or density of tobacco retail outlets and several jurisdictions have proposed bans on the location or restrictions on the number of outlets. However, evidence of the effect of reducing outlets on smoking behaviours is limited, due to the lack of intervention studies. To date, the evidence of the effects of access to tobacco on smoking behaviours is primarily derived from cross-sectional and a few longitudinal studies. $^{4-9}{ }^{11-13}$ One such longitudinal study found that among men (but not women) who were moderate/heavy smokers at baseline, living $<0.50 \mathrm{~km}$ walking distance from the nearest tobacco outlet was associated with 27\% lower likelihood of smoking cessation (95\% CI $12 \%$ to $40 \%$ ), compared to those living farther away. ${ }^{5}$ Even though some jurisdictions (in San Francisco in 2014, Hungary in 2013, ${ }^{14}$ and Mecca and Medina in 2001) have introduced policies to restrict the availability of tobacco, the (long-term) effect of these measures on smoking prevalence, population health or costs have not been evaluated to date.

In terms of modelling studies, the evidence is also incomplete. Our previous research estimated the largest impact on NZ smoking prevalence from reducing sales to half of the liquor stores and nowhere else $(0.8 \%$ overall reduction by 2025$)$ and the least impact from eliminating tobacco outlets within $1 \mathrm{~km}$ of schools ( $0.2 \%$ overall reduction). ${ }^{15}$

While the collective evidence is still modest, the political precedent for regulating the number, location or density of particular types of businesses could make outlet reduction interventions an appealing component of a larger endgame strategy. Furthermore, there may be added benefits through the denormalisation of tobacco purchasing (and smoking) through reductions in retail availability. Still, the cost-effectiveness of associated reductions in smoking-related disease from tobacco outlet reduction interventions is unknown.

This research aimed to quantify the potential population-level future health gain and the health system costs for four different tobacco retail outlet restriction interventions. A combination of geographic, economic and epidemiological approaches were used to evaluate the cost-effectiveness of the following interventions: (1) reduce the total number of tobacco retail outlets by 95\%; (2) 
permit sales at half the liquor stores (and nowhere else); (3) eliminate sales from outlets within $1 \mathrm{~km}$ of schools and (4) eliminate sales from outlets within $2 \mathrm{~km}$ of schools. ${ }^{15}$

\section{METHODS}

\section{Model overview}

We adapted a previously published multistate life-table model, ${ }^{16}$ to estimate the impacts of outlet reduction interventions on 16 tobacco-related diseases (see online supplementary appendix). This section summarises key aspects. Disease input parameters included incidence, prevalence and case-death rates for each disease, for the NZ population beginning in 2011. Outlet reduction interventions change disease rates, leading to years of life saved which were adjusted for disability. The base model included trends over time in incidence, remission and casedeath, included cost uncertainties, and used a discount rate of $0 \%$.

Four legally mandated reductions in outlets were modelled, phased-in over 10 years (2011-2021), by estimating increases in distance and time travelled along roads from neighbourhood centres (census area units (CAUs); median area $=3 \mathrm{~km}^{2}$ ) to the reduced number and locations of outlets, using ArcGIS (ESRI, Redlands, California, USA). Increases in travel distance to tobacco outlets was used to determine travel costs (in terms of valuation of time and vehicle running costs), which were converted to increases in the notional cost of a pack of cigarettes. Price elasticities for tobacco demand (specifically smoking prevalence elasticities) by age and ethnicity were then used to estimate changes in smoking behaviours and thus disease rates. Then the difference in quality-adjusted life years (QALYs) between business-as-usual (BAU) and under the interventions was estimated and compared across different population groups. QALYs gained and cost-savings were calculated over the remainder of the 2011 cohort's lifetime.

\section{Model parameters}

Disease parameters and smoking relative risks

Inclusion criteria for disease outcomes in this study were: (1) inclusion in the NZ Burden of Disease Study (NZBDS); ${ }^{17}$ (2) inclusion in the NZ Census Mortality Study on smoking and cancer ${ }^{18}$ and had significant smoking-related relative risks (RRs) and (3) contribution to at least $0.5 \%$ of the total disease burden in NZ in 2006 (as measured in disability-adjusted life years in the NZBDS). Disease incidence, mortality, prevalence, casedeath data and uncertainty on disease parameters were calculated based on our previous work, ${ }^{15}$ and described in an online supplementary appendix. But briefly, parameters for 1 year age groups by sex and ethnicity were used to populate the multistate life-table model. Disability rates were calculated for each age, sex and ethnicity group using disease-specific, corrected prevalent years lived with disability, or pYLDs (adjusted for other comorbidities).

The relative risks of current smokers compared to never smokers were calculated, using mainly NZ sources outlined in published work using a version of this mode ${ }^{16}$ (see also online supplementary appendix). The current-never relative risk was specified to decay for ex-smokers using equations by Hoogenveen $e t a l^{19}$ and we assumed no excess risk after 20 years.

\section{Health system and intervention costs}

Health system costs by sex and age group, in 2011 NZ dollars, were determined using data for publicly funded health events occurring 2006-2010 (hospitalisations, inpatient procedures, outpatients, pharmaceuticals, laboratories and expected primary care usage). ${ }^{16}$ Each year, average health system costs (excluding the last 6 months of life) for non-tobacco diseases were assigned to all 'alive' members of the cohort based on age and sex. Subsequently, excess costs for tobacco-related diseases were assigned by the first year of diagnosis or in the last 6 months of life if dying of the given disease and, otherwise, for prevalent cases of each disease. Health system costs over the cohort's lifetime were then modelled for BAU and for each intervention.

The cost of the tobacco outlet reduction interventions was given the previously estimated costs of a new law in NZ, mandating tobacco outlet restrictions (NZ\$3.54 million). ${ }^{20}$

\section{Intervention specification}

Based on previous research, ${ }^{15}$ the following four interventions were specified, with intervention parameter details in table 1 . Our general approach of requiring a legally based intervention (a law requiring a licence and restrictions on the number, type of store or location) is supported by NZ survey data indicating the unlikely success of voluntary measures by retailers. ${ }^{21}$ We assumed that licences would be issued by annual auction, whereby the eligible outlets in the most densely populated areas would be most likely to win the licence at auction.

1. Reduce the total number of outlets by $95 \%$-'Reduce $95 \%$ '. This intervention involved progressive reductions in licences, until only $5 \%$ of the current outlets would be permitted to sell tobacco.

2. Permit sales at half the liquor stores and nowhere else - '50\% Liquor only'. This intervention progressively limited tobacco sales to just $50 \%$ of liquor stores $(\mathrm{n}=386$ stores nationwide in NZ), to make use of existing official compliance and monitoring structures required for such outlets.

3. Eliminate sales from outlets within $1 \mathrm{~km}$ of schools-' $1 \mathrm{~km}$ schools'. Annually expanding buffer rings (in which tobacco sales were banned) were used around all schools (primary, intermediate and secondary) at even increments to reach a maximum buffer size of $1 \mathrm{~km}$ at year 10 .

4. Eliminate sales from outlets within $2 \mathrm{~km}$ of schools-' $2 \mathrm{~km}$ schools'. Similar to intervention (iii) above, except buffer rings reached a maximum buffer size of $2 \mathrm{~km}$ at year 10 .

For these four interventions, travel along road networks from neighbourhood centres to the nearest tobacco outlet was calculated for each year to estimate increases in costs from reduced access to retail outlets. Estimated cost increases included the costs associated with travel (ie, fuel and car maintenance) and those related to travel time, as represented in an example (figure 1). Specifically, distances were assigned travel costs using the Ministry of Health mileage reimbursement rate for private vehicles under the National Travel Assistance Scheme (NZ\$ 0.28 per $\mathrm{km}$ (2011 NZ dollars)). ${ }^{22}$ Distances were also converted into time spent travelling (assuming $50 \mathrm{~km}$ per hour in urban/semiurban areas and $70 \mathrm{~km}$ per hour in rural areas) and assigned the car, non-work travel time value from the NZ Transport Agency (NZ\$7.18 per hour). ${ }^{23}$

To take account for geographic heterogeneity in travel costs, neighbourhoods were divided into three categories: urban, semiurban and rural. Average net costs were then weighted by the proportion of Māori (indigenous population) and non-Māori within each area type. According to the $2006 \mathrm{NZ}$ census, the proportions of Māori/non-Māori in urban, semiurban and rural areas were $81.2 / 84.2 \%, 9.0 / 8.8 \%$ and $9.8 / 7.0 \%$, respectively. The resulting ethnicity-specific costs were then applied as notional increases in the pack price of tobacco. Baseline costs 
Table 1 Intervention input parameters

\begin{tabular}{ll}
\hline Parameter & Assumptions and data source data \\
\hline Cost of a law & Costs of a new law in NZ to mandate the tobacco retail outlet \\
& reduction interventions: NZ\$3.54 million. We did not consider \\
& ongoing costs around auction operation or retailer licensing since \\
& we assumed that this would be self-financing from auction fees. \\
& Also we did not assume any costs to businesses since it was \\
& assumed that they would replace tobacco sales with other \\
product sales (retail outlets that only sell tobacco are very rare in & NZ).
\end{tabular}

Travel costs (treated as an incremental increase in the price of a pack of 20 cigarettes)

Tobacco price elasticities used to estimate the impact of increased travel costs on tobacco consumption

Illicit tobacco market dynamics
The incremental travel costs for each intervention year were calculated using: (1) a monetary value on distance travelled (eg, fuel, car maintenance, but excluding insurance and depreciation cost), (2) a monetary value on time spent travelling (ie, personal non-work-related travel time) and (3) an increasing proportional rate for the fraction of the total trip (and hence the travel costs) that would be tobacco-related. ${ }^{15}$ We used the NZ Ministry of Health mileage reimbursement rate for private vehicles under the National Travel Assistance Scheme: \$0.28/km (2011 NZ\$). ${ }^{22}$ We used the car, non-work-related travel time value of $\$ 7.18$ per hour (2011 NZ\$). ${ }^{23}$ Costs were calculated for each neighbourhood centre and then averaged by rural, semiurban or urban area types. Costs were then weighted by the proportion of Māori and non-Māori in each area type to produce costs by ethnicity for each intervention and each year. We assumed that the progressive reduction in outlets over time would increase the proportion of travel (and thus the total travel costs) that is tobacco-related. Each year, the proportion of tobacco-related travel increased by $5 \%$, up to $50 \%$ in year 10 .

Non-Māori: The following price elasticities for smoking prevalence were used: -0.38 (for $15-20$ years), -0.29 (for $21-$ 24 years), -0.19 (for $25-34$ years) and -0.10 (for $35+$ years; as per our previous published work ${ }^{30}$ ). These were applied in the year the travel costs increased as a result of reducing the number of tobacco retail outlets under the four different interventions. Māori: For each intervention, we scaled up the non-Māori price elasticity by $20 \%$ for Māori given economic theory, the patterns in the international literature for other social groupings and some NZ evidence for increased price sensitivity for Māori for tobacco and for food products. ${ }^{31} 32$

The illicit tobacco market was set to start at $1 \%$ of the market share in 2011 based on the best data at that time. ${ }^{3}$ The average tobacco price used in the modelling was a combined function of the legal market price of tobacco, the illicit price of tobacco ( $75 \%$ of the legal price which we estimated from Australian work in the absence of NZ data ${ }^{33}$ ) and the size of the illicit market. In the best model, we assumed a stable illicit market (as per our previous work ${ }^{15}$ and reflecting the absence of commercial tobacco growing in NZ). But in a scenario analysis, we assumed a growing illicit market, whereby every $10 \%$ increase in the price of a pack of 20 cigarettes would result in a $1 \%$ increase in the size of the illicit market.
Trend and uncertainty

Uncertainty: $\gamma, \mathrm{SD}=\mathrm{NZ} \$ 1.05$ million in 2011 only. ${ }^{20}$

An uncertainty with a log-normal distribution of $\pm 20 \%$ SD around the running cost of a car was assumed. An uncertainty with a log-normal distribution of $\pm 20 \%$ SD around the value on personal travel time was assumed. An uncertainty with a $\beta$-distribution of $\pm 20 \%$ SD around the amount of travel explicitly for tobacco was assumed. Total cost uncertainty: log-normal distribution, $\pm 25 \%$ SD. Uncertainties around costs and the amount of travel explicitly for tobacco were mathematically combined in the total travel cost formulae. The formula was run a 1000 times with Monte Carlo simulation for each intervention year in TreeAge software.

No trend.

Uncertainty: Non-Māori, SD $\pm 20 \%$, normal, correlated 1.0 across four age groups; Māori absolute scalar of $+20 \%$ within each age group, $\pm 10 \%$ normal (ie, $95 \%$ range of absolute scalar of $0.4 \%$ to $39.6 \%$ ).

Uncertainty of $\pm 20 \%$ SD $\beta$ around the illicit price of tobacco. were the sum of estimated pack price (\$14.50 for a 20-cigarette pack) ${ }^{16}$ plus travel costs under current conditions (with all existing outlets). Intervention net costs for the first year were calculated by subtracting baseline costs from the intervention costs. Intervention costs for subsequent years were incremental increases over the previous year, without inflation.

These changes in notional pack price costs for the interventions influenced smoking prevalence through age- specific and ethnicity-specific price elasticities, whereby the base model included 20\% higher price elasticities for Māori compared to non-Māori (as per previously published $\operatorname{work}^{16}$ ). Intervention effects applied in the year of the phased intervention only, consistent with other tobacco intervention models. ${ }^{16}$ The difference between BAU and future tobacco prevalence projections under the four interventions was combined with the relative risks to calculate population impact fractions and ultimately the percentage reduction in incidence of each tobacco-related disease. Finally, QALYs gained and health system cost-savings were then reported for the remainder of the 2011 cohort's lifetime.

\section{Uncertainty and scenario analysis}

We used a $0 \%$ discount rate (base model) and a 3\% discount rate when calculating QALYs gained and health system costs saved for each intervention. Uncertainty around the incremental travel costs (explained in more detail in table 1) was determined from the uncertainty in the running cost of a car, the value of time spent in car travel and the amount of travel explicitly performed for the goal of purchasing tobacco, using Monte Carlo analysis. We also included uncertainties in the cost of a law, price elasticities, BAU smoking prevalence trends, health system costs and morbidity, all as specified in published work using a version of this model. ${ }^{16}$ 


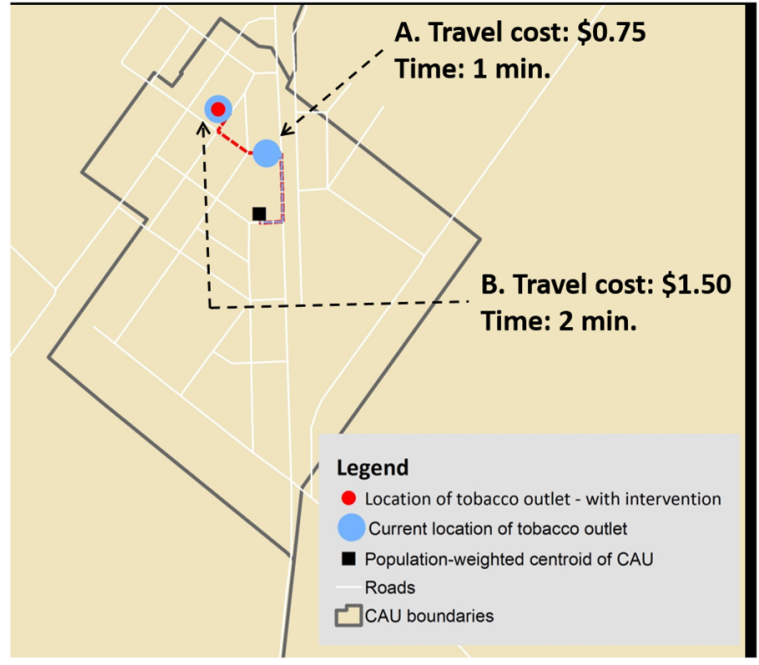

Figure 1 Example of travel cost estimation through reduction in tobacco outlets.

We ran a scenario analysis where non-Māori life expectancy and disability weights by age were used for Māori, in an effort to avoid penalising Māori because of higher background rates of mortality and morbidity (which can be considered an 'equity analysis ${ }^{24}$ ). We also evaluated scenarios for varying the discount rate (up to $3 \%$ and $6 \%$ ), varying price elasticities and around the assumption of potential growth of the illicit tobacco market.

\section{RESULTS}

All interventions led to reductions of $89 \%$ or more of current tobacco outlets as detailed in our previous modelling work ${ }^{15}$ (albeit with some model refinements). The more concentrated location of final outlets in the more major population centres with the ' $50 \%$ Liquor only' intervention added to its effectiveness. Indeed, under this ' $50 \%$ Liquor only', the notional cost (reflecting direct and indirect costs) of a 20-cigarette pack increased to NZ\$51 in rural areas and \$23 in urban areas, yielding the highest cost of cigarettes of all interventions in 2021 at the end of the 10-year phase-in (see online supplementary appendix table A6). Furthermore, this particular intervention was estimated to result in a reduction of smoking prevalence in the population from $9.9 \%$ (under business as usual) to $9.1 \%$ in 2025 (the year of NZ's proposed smoke-free nation goal; see online supplementary appendix table A6).

In terms of health gain, permitting sales at $50 \%$ of the liquor stores (and nowhere else) had the highest estimated impact on smoking reduction and hence health gains (at 129000 QALYs, table 2). This was 1.5 times the QALYs gained from the intervention eliminating sales within $2 \mathrm{~km}$ of schools, the next most effective intervention (table 2).

All interventions were cost-saving, over the remainder of the 2011 population's lifetime with the most effective intervention '50\% Liquor only' achieving savings of NZ\$1.82 billion (US $\$ 1.23$ billion, table 2 ). All interventions remained cost-saving at a discount rate of $3 \%$ (table 2), but also at $6 \%$ (eg, see table 3 and online supplementary appendix table A7).

Scenario analyses around the most effective intervention '50\% Liquor only' found that per capita QALY gains were five times greater for Māori compared to non-Māori (93.7 vs 17.7 per 1000 population, respectively; table 3). QALY gains for Māori also became even more pronounced in the additional 'equity analysis' scenario where the 'envelope' for future health gain was expanded to be equivalent to that for non-Māori (table 3). Changing price elasticities had a moderate impact on health gain and costs-but the intervention always remained cost-saving. There was relatively little change in baseline results when the scenario around the assumed growth of the illicit tobacco market was considered (table 3 ).

\section{DISCUSSION}

Main findings and interpretation

This is the first study (to the best of our knowledge) to model tobacco outlet reductions and estimate future health gains and health system cost-savings at the population level. This study found that restricting tobacco sales to only $50 \%$ of the country's liquor stores and no other outlets was the most effective of the four interventions, as it led to the highest travel costs and therefore the highest notional pack price. It then led to the highest health gains and also to large cost-savings (NZ\$1.03 billion), though all four interventions were cost-saving for the health system. Comparisons of cost-effectiveness across studies in different populations and using different models are challenging, due to differences in modelling assumptions, population characteristics and intervention specification. However, in our other tobacco control intervention research, using similar methods as this study, a $10 \%$ annual tax increase on tobacco from 2011 to 2031 led to twice the QALYs gained compared to this study's '50\% Liquor only' intervention (123000 QALYs). ${ }^{16}$

In Australia (five times the population of NZ), tobacco control mass media campaigns have resulted in an estimated 407000 QALYs gained and an estimated cost-savings of AU $\$ 40.6$ million, over the remaining lifetime of 190000 quitters censored at 85 years. ${ }^{25}$ In the USA, the federally funded Centers for Disease Control and Prevention antismoking campaign (Tips From Former Smokers (Tips)) indicated a cost of US\$268 per QALY gained. ${ }^{26}$

The most effective tobacco outlet intervention yielded per capita QALY gains about five times greater for Māori, similar to

Table 2 QALYs gained and health system cost savings, by outlet reduction intervention New Zealand, 2011*

\begin{tabular}{|c|c|c|c|c|}
\hline \multirow[b]{2}{*}{ Outlet reduction interventions } & \multicolumn{2}{|l|}{ Discount rate $=0 \%$} & \multicolumn{2}{|l|}{ Discount rate $=3 \%$} \\
\hline & QALYs gained & $\begin{array}{l}\text { Net health system } \\
\text { cost-savings (NZ\$ million) }\end{array}$ & QALYs gained & $\begin{array}{l}\text { Net health system } \\
\text { cost-savings (NZ\$ million) }\end{array}$ \\
\hline 'Reduce 95\%' & 37900 (21 100 to 65600$)$ & $\$ 540$ (297 to 913$)$ & 8040 (4720 to 13000$)$ & $\$ 161$ (92.6 to 263$)$ \\
\hline '50\% Liquor only' & $129000(74100$ to 212000$)$ & $\$ 1820$ (1030 to 2960$)$ & $26500(15600$ to 42100$)$ & $\$ 525$ (302 to 829$)$ \\
\hline '1 km schools' & 32000 (17 200 to 54300$)$ & $\$ 451$ (243 to 755$)$ & 6590 (3740 to 11000$)$ & $\$ 131$ (73.1 to 220$)$ \\
\hline '2 km schools' & 84800 (48 400 to 138000$)$ & $\$ 1200$ (682 to 1990$)$ & 18000 (10 200 to 29300$)$ & $\$ 357$ (199 to 593$)$ \\
\hline
\end{tabular}




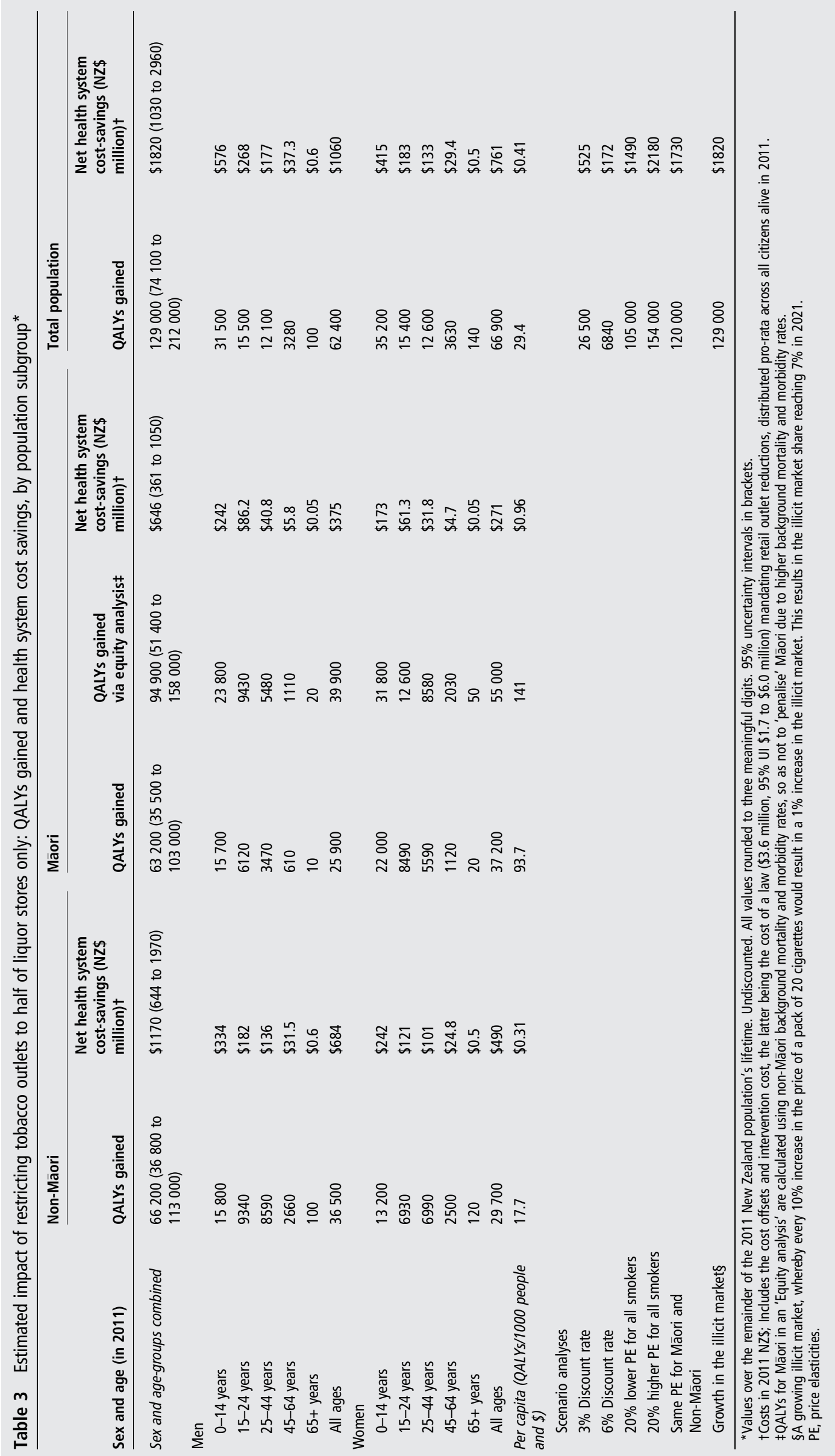


the ratio for our tobacco tax intervention modelling. ${ }^{16}$ This is due to higher background smoking prevalence and estimated higher price sensitivity among Māori. Our current model assumes incident rate ratios for current smokers compared to never smokers to be the same for Māori and non-Māori. However, recent analyses, by us, of linked census mortality data for 2006-2011 find stronger mortality rate ratios for non-Māori (as yet unpublished). It was beyond the scope of this paper to include probable parallel ethnic heterogeneity in incident rate ratios, but we estimate that this will translate to per capita QALY gains being perhaps four times as great for Māori than non-Māori rather than the five times greater, as estimated in this paper. Still, these interventions show a large inequality reducing effect.

The results of this study, given the assumption that tobacco outlet reduction impacts on smoking can be substantially captured through indirect price increases from increased travel, are most likely broadly generalisable to other developed countries with declining smoking prevalence, highly urbanised populations and high levels of access to tobacco retailers currently. Even so, they would need a well-organised government to pass the relevant enabling law and a non-corrupt bureaucracy to run the licensing system and to enforce the law. The plausibility of such interventions may also depend on opposition efforts by tobacco manufacturers and retailers. Also the impact would depend on the cost of transport and the value of personal time spent travelling. So, in the USA, where the costs of fuel and running a car are cheaper than most other developed countries, the impact might be less. But, in Europe, where these costs are higher (and car ownership levels are lower), the impact might be higher.

\section{Strengths and limitations}

This study benefited from using an established model that included 16 tobacco-related diseases and rich epidemiological and health system cost data. The setting of a country with an endgame goal and a very limited illicit tobacco market ${ }^{3}$ also gives such modelling additional plausibility.

We attempted to address sources of uncertainty for input parameters in our model specification. We also ran three scenarios for one key source of uncertainty-price elasticities. Nevertheless, a primary limitation of this research was the reliance on price elasticities from the tobacco tax literature, which are based on direct costs faced by smokers. While some economic research indicates that travel costs can be assumed to be similar to tobacco pack price changes, travel time and travel costs are more indirect and therefore, it is unknown whether price elasticities for changes in travel costs are different to those arising from tax-induced changes. Future studies making use of longitudinal data sets on health, smoking and access to tobacco retailers (eg, the Finnish cohort ${ }^{5}$ ) may be able to validate, or recalibrate, the price elasticity methods associated with increased travel to purchase tobacco used here.

The potential health gains of our outlet reduction interventions may also be conservative due to model structure. That is, we did not include any health gain from reduced tobacco consumption by smokers who did not quit. Also we did not include any health gain from reduced exposure of non-smokers to secondhand smoke and some other tobacco-related conditions (eg, asthma).

Also, in terms of the intervention specification it was assumed that in the auction system, densely populated places would be able to bid at higher levels due to higher revenues. If the interventions had specifically restricted outlets in the most densely populated areas (rather than using an auction system), health gains and cost-savings would likely increase.

It is also likely that making smoking and tobacco purchasing less visible through outlet reductions could help denormalise smoking and thus increase the decline in smoking prevalence (ie, positive spill-over effects) and the health gains associated with these interventions. Some evidence from evaluating the impacts of bans on point-of-sale displays of tobacco products at least suggests that such measures could support further denormalisation of smoking among youth. ${ }^{27-29}$

\section{Implications for further research and policy}

The estimated effects of these four tobacco retail outlet interventions were smaller than those estimated for $10 \%$ annual tax increases in the same population, ${ }^{16}$ suggesting that policymakers may wish to prioritise tobacco tax increases over retail outlet reductions. Nevertheless, these outlet reduction interventions may have greater political traction related to child protection, especially when eliminating sales near schools. Also, they can potentially be combined as part of building a more comprehensive tobacco control programme.

\section{CONCLUSIONS}

These four modelled tobacco outlet reduction interventions reduced smoking prevalence, achieved health gains and saved health system costs. A key assumption, however, was that increased travel requirements can be operationalised as being equivalent to a price increase in tobacco. If outlet reductions have spill-over effects (eg, denormalisation) on tobacco demand greater than that reflected in travel time and cost, then the effects will be larger than those estimated here. Outlet reduction should be considered alongside additional interventions with greater estimated health improvements, such as annual tobacco tax increases.

\section{What this paper adds}

- There is increasing policy and research interest in restrictions on tobacco retail outlet locations and density, including for achieving tobacco endgame goals.

- This study used an established tobacco control model, modelling reduced outlet availability in terms of increased travel costs, to study four outlet reduction interventions at a country level (New Zealand). It found that the most effective was one that limited tobacco sales to $50 \%$ of liquor outlets (and nowhere else). But other interventions, such as retail-free zones around schools, were also effective and also achieved net cost-savings to the health system.

- The interventions should reduce health inequalities with around five times the per capita health gain for Māori (indigenous) compared to non-Māori.

- These interventions were still not as effective as increases in tobacco tax (using the same model and assuming outlet reductions can be modelled as a cost increase to the smoker), but ultimately they could be combined with such strategies in comprehensive tobacco control programmes.

Contributors ALP and NW conceived of the study. LJC, TB and GK conceived of the modelling approach. ALP led the geographic analyses. CLC, FSvdD, GK and NN ran the analyses through the multistate life-table model. FSvdD and GK led uncertainty analyses around travel cost input parameters. TB and NW supervised all 
analyses and interpretation. All authors contributed to writing and editing the manuscript.

Funding ALP, LJC, TB, GK, CLC, NN and NW were supported by the BODE ${ }^{3}$ Programme which is studying the effectiveness and cost-effectiveness of various health system interventions and receive funding support from the Health Research Council of New Zealand (grant number 10/248). FSvdD is supported by a University of Otago Doctoral Scholarship.

Competing interests None declared.

Provenance and peer review Not commissioned; externally peer reviewed.

Data sharing statement Model input parameters have been published as an online supplementary appendix.

\section{REFERENCES}

1 New Zealand Government, Government Response to the Report of the Māori Affairs Committee on its Inquiry into the tobacco industry in Aotearoa and the consequences of tobacco use for Māori (Final Response). Wellington: New Zealand (NZ) Parliament, 2011. http://www.parliament.nz/en-nz/pb/presented/papers/ 49DBHOH_PAP21175_1/government-final-response-to-report-of-the-m\%c4\% 81 ori-affairs

2 Statistics New Zealand. Quitting and not starting-smoking in New Zealand decreases. 2013 (cited 15 September 2015). http://www.stats.govt.nz/Census/ 2013-census/data-tables/totals-by-topic-mr2.aspx

3 Ajmal A, U VI. Tobacco tax and the illicit trade in tobacco products in New Zealand. Aust N Z J Public Health 2015;39:116-20.

4 Chuang YC, Cubbin C, Ahn D, et al. Effects of neighbourhood socioeconomic status and convenience store concentration on individual level smoking. J Epidemiol Commun Health 2005;59:568-73.

5 Halonen Jl, Kivimäki M, Kouvonen A, et al. Proximity to a tobacco store and smoking cessation: a cohort study. Tob Control 2014;23:146-51.

6 Lipperman-Kreda S, Grube JW, Friend KB. Local tobacco policy and tobacco outlet density: associations with youth smoking. J Adolesc Health 2012;50:547-52.

7 Mistry R, Pednekar M, Pimple S, et al. Banning tobacco sales and advertisements near educational institutions may reduce students' tobacco use risk: evidence from Mumbai, India. Tob Control 2013;24:e100-7.

8 Reitzel LR, Cromley EK, Li Y, et al. The effect of tobacco outlet density and proximity on smoking cessation. Am J Public Health 2011;101:315-20.

9 West JH, Blumberg EJ, Kelley NJ, et al. Does proximity to retailers influence alcohol and tobacco use among Latino adolescents? I Immigr Minor Health 2010;12:626-33.

10 Young-Wolff $K$, Henriksen L, Delucchi K, et al. Tobacco retailer proximity and density and nicotine dependence among smokers with serious mental illness. Am J Public Health 2014;104:1454-63.

11 Cantrell J, et al. The impact of the tobacco retail outlet environment on adult cessation and differences by neighborhood poverty. Addiction 2015;110:152-61.

12 Kite J, Anesetti-Rothermel A, Pearson JL, et al. Tobacco outlet density and social disadvantage in New South Wales, Australia. Tob Control 2014;23:181-2.

13 Marashi-Pour S, Cretikos M, Lyons $C$, et al. The association between the density of retail tobacco outlets, individual smoking status, neighbourhood socioeconomic status and school locations in New South Wales, Australia. Spat Spatiotemporal Epidemio/ 2015;12:1-7.
14 Henriksen L. The retail environment for tobacco: a barometer of progress towards the endgame. Tob Control 2015;24:e1-2.

15 Pearson AL, van der Deen FS, Wilson N, et al. Theoretical impacts of a range of major tobacco retail outlet reduction interventions: modelling results in a country with a smokefree nation goal. Tob Control 2015;24:e32-8.

16 Blakely T, Cobiac LJ, Cleghorn CL, et al. Health, health inequality, and cost impacts of annual increases in tobacco tax: multistate life table modeling in New Zealand. PLoS Med 2015:12:e1001856.

17 Ministry of Health. Ways and means: a report on methodology from the New Zealand Burden of Disease, Injury and Risk Study, 2006-2016. Wellington: Ministry of Health, 2013.

18 Blakely T, Carter K, Wilson N, et al. If nobody smoked tobacco in New Zealand from 2020 onwards, what effect would this have on ethnic inequalities in life expectancy? N Z Med J 2010;123:26-36.

19 Hoogenveen RT, van Baal PH, Boshuizen HC, et al. Dynamic effects of smoking cessation on disease incidence, mortality and quality of life: the role of time since cessation. Cost Eff Resour Alloc 2008;6:1.

20 Wilson N, Nghiem N, Foster R, et al. Estimating the cost of new public health legislation. Bull World Health Organ 2012;90:532-9.

21 Paynter J, Glover M, Bullen C, et al. An intervention to reduce the number of convenience stores selling tobacco: feasibility study. Tob Control 2016;25:319-24.

22 Ministry of Health. Guide to The National Travel Assistance (NTA) policy 2005: August 2009. Wellington: New Zealand Ministry of Health, 2009. http://www. health.govt.nz/our-work/hospitals-andspecialist-care/national-travel-assistancescheme

23 New Zealand Transport Authority. Economic evaluation manual. Wellington: New Zealand Transport Agency, 2010:A4-2.

24 McLeod M, Blakely T, Kvizhinadze $G$, et al. Why equal treatment is not always equitable: the impact of existing ethnic health inequalities in cost-effectiveness modeling. Popul Health Metr 2014;12:15.

25 Hurley S, Matthews J. Cost-effectiveness of Australian National Tobacco Campaign. Tob Control 2008;17:379-84.

$26 \mathrm{Xu}$ X, Alexander RL Jr, Simpson SA, et al. A cost-effectiveness analysis of the first federally funded antismoking campaign. Am J Prev Med 2015;48:318-25.

27 Dunlop S, Kite J, Grunseit AC, et al. Out of sight and out of mind? Evaluating the impact of point-of-sale tobacco display bans on smoking-related beliefs and behaviors in a sample of Australian adolescents and young adults. Nicotine Tob Res 2015;17:761-8.

28 Levy DT, Lindblom EN, Fleischer NL, et al. Public health effects of restricting retail tobacco product displays and ads. Tob Regul Sci 2015;1:61-75.

29 Scheffels J, Lavik R. Out of sight, out of mind? Removal of point-of-sale tobacco displays in Norway. Tob Control 2013;22:e37-42.

30 Cobiac L, Ikeda T, Nghiem N, et al. Modelling the implications of regular increases in tobacco taxation in the tobacco endgame. Tob Control 2015;24:e154-60.

31 Grace RC, Kivell BM, Laugesen M. Predicting decreases in smoking with a cigarette purchase task: evidence from an excise tax rise in New Zealand. Tob Control 2015;24:582-7.

32 Ni Mhurchu C, Eyles $\mathrm{H}$, Schilling $\mathrm{C}$, et al. Food prices and consumer demand: differences across income levels and ethnic groups. PLOS ONE 2013;8:e75934.

33 Scollo M, Bayly M, Wakefield M. Availability of illicit tobacco in small retail outlets before and after the implementation of Australian plain packaging legislation. Tob Control 2015;24:e45-51. 